\title{
Properties of biomass-derived biochars: Combined effects of operating conditions and biomass types
}

\author{
Lei Luo ${ }^{\mathrm{a}}$, Chuang $\mathrm{Xu}^{\mathrm{a}, \mathrm{b}}$, Zien Chen ${ }^{\mathrm{a}}$, Shuzhen Zhang ${ }^{\mathrm{a}, *}$

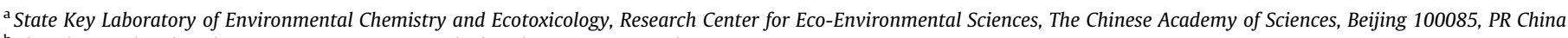 \\ ${ }^{\mathrm{b}}$ Shenzhen Techand Ecology E' Environment Co., Ltd, Shenzhen 518040, PR China
}

\section{H I G H L I G H T S}

- Combined effects of operating conditions on biochar properties were investigated.

- Temperature and atmosphere act as key factors determining biochar properties.

- DOC molecular weight varies with biomass type and increases with temperature.

- Phase transition of biomass structures occurs at around $400{ }^{\circ} \mathrm{C}$.

- Environmental risks from biochar-derived DOC deserve much attention.

\section{A R T I C L E I N F O}

\section{Article history:}

Received 3 February 2015

Received in revised form 14 May 2015

Accepted 15 May 2015

Available online 20 May 2015

\section{Keywords:}

Biochar

Production temperature

Atmosphere

Dissolved organic carbon

Functional group

\begin{abstract}
A B S T R A C T
Combined effects of operating conditions including heating temperature $\left(200-700{ }^{\circ} \mathrm{C}\right)$, time $(1-8 \mathrm{~h})$ and rate, and atmosphere (air-flow, air-limited and $\mathrm{N}_{2}$ ) on the physicochemical properties of biochars with pine sawdust, maize straw and sugarcane bagasse as feedstocks were investigated. The results demonstrated that production temperature and atmosphere acted as the predominant factors that determined the properties of biochars. The X-ray diffraction data confirmed the occurrence of phase transition in the biomass structures at around $400{ }^{\circ} \mathrm{C}$. Heating time and rate showed little effect on the functional group compositions of the biochars within $8 \mathrm{~h}$, particularly under $\mathrm{N}_{2}$ atmosphere. In addition, the molecular weights of the biochar-derived dissolved organic carbon tended to increase with increasing temperature. Feedstock type also affected the biochar properties by the compositional differences in mineral salts and cellulose/lignin in the three biomass materials. This work provides important information for optimizing procedures for biochar production with desired properties and high yield.
\end{abstract}

(c) 2015 Elsevier Ltd. All rights reserved.

\section{Introduction}

Biochar, a carbonaceous solid product of pyrolysis or incomplete combustion of organic materials, has been receiving increasing attention in various environmental applications due to its strong affinity for contaminants (Ghosh et al., 2011; Uchimiya et al., 2011; Shen et al., 2012) and ability for carbon sequestration (Lehmann, 2007). Previous researches have demonstrated that biochars with different functional group compositions show contrasting affinity for inorganic (heavy metals, for instance) (Shen et al., 2012) and organic contaminants (Zhu et al., 2005; Chen et al., 2012). Selection of proper biochars produced at optimized conditions, which are suitable for sequestration/immobilization of

* Corresponding author at: 18 Shuangqing Rd, Haidian, Beijing 100085, PR China Tel.: +8610 62849683.

E-mail address: szzhang@rcees.ac.cn (S. Zhang). specific contaminants, should be critical to improve their efficiency as soil amendments (Al-Wabel et al., 2013). Therefore, developing procedures for producing biochars with intended properties is necessary for specific environmental/agricultural purposes (Zhao et al., 2013).

Properties of biochars are strongly dependent on biomass feedstocks and production conditions (Enders et al., 2012; Rutherford et al., 2012). Numerous studies have attempted to explore the relationships between biochar properties and pyrolysis conditions (Sensöz and Angin, 2008; Keiluweit et al., 2012; Zhao et al., 2013). However, by detailed analysis we find that most of these studies only investigate the impacts of one or two production parameters such as temperature (Al-Wabel et al., 2013; Lattao et al., 2014) and temperature plus heating rate (Angin, 2013) on the properties of biochars in order to get proper biochars for carbon sequestration and contaminant adsorption, and that the effect of atmosphere for biochar production was mostly neglected. 
Systematic investigation on the combined effects of feedstock types and various operating conditions including atmospheric conditions, heating time, rate and temperature on biochar properties is still lacking (Mukherjee et al., 2011; Keiluweit et al., 2012; Zhao et al., 2013). At the same time, there is a great concern with the environmental problems associated with greenhouse gas emissions and energy consumption during the biochar production (Roberts et al., 2010). Obtaining intended physicochemical properties while improving yield is highly desirable for biochar production (Manyà, 2012; Veksha et al., 2014). Consequently, efforts must be made to present optimized procedures for biochar production, which can be helpful in reaching a compromise between obtaining biochars with desired properties and reducing environmental costs with high yields and less energy consumption (Mukherjee et al., 2011; Manyà, 2012; Al-Wabel et al., 2013).

Current studies on the characteristics of biochars mainly focused on their chemical functionality related to agricultural and environmental applications. However, the properties of dissolved organic carbon (DOC) derived from biochars have received scarce attention (Mukherjee and Zimmerman, 2013). For instance, most researchers tended to remove DOC from biochars before property characterization (Chun et al., 2004; Cheng et al., 2006; Uchimiya et al., 2011; Mukherjee et al., 2011). It has been demonstrated that the properties of DOC profoundly affect the sequestration and fates of nutrients and contaminants (Luo et al., 2011) as well as the stability of biochars in the environment (Zimmerman, 2010). It is expected that an investigation on the properties of biochar-derived DOC and their relationships with production conditions will facilitate the applications of biochars and the understanding of their fate in the environment.

The objectives of this study were therefore to evaluate the effects of production temperature, atmosphere, and heating time and rate on the properties of biochars and to determine the relative importance of the operating condition parameters with respect to the desired properties. Particularly, the properties of the biochar-derived DOC under different conditions were for the first time characterized. Economically favorable procedures for intended biochars with desirable properties and high yield will be proposed based on the tested conditions. To this end, optimizing studies were carried out on three different biomass materials including pine sawdust, maize straw and sugarcane bagasse as potential feedstocks for biochar production.

\section{Methods}

\subsection{Biochar feedstocks}

Three biomass materials including pine (Masson pine, Pinus massoniana Lamb) sawdust, maize (Zea mays L.) straw and sugarcane (Saccharum officinarum L.) bagasse (sugarcane following industrial processing) were used as feedstocks for biochar production. All the feedstocks were dried at $80^{\circ} \mathrm{C}$ for at least $48 \mathrm{~h}$, and then pulverized to less than $2 \mathrm{~mm}$ for biochar production.

\subsection{Biochar production}

The three biomass feedstocks were either placed in a thin layer and combusted in a $0.012 \mathrm{~m}^{3}$ muffle furnace under aerobic condition or tightly packed into ceramic pots, covered with fitting lids and alumina foils, and then pyrolyzed under oxygen-limited condition, respectively. For the aerobic condition experiments, samples were heated at $200,250,300,350$ and $400{ }^{\circ} \mathrm{C}$ under air purge $(1.0 \mathrm{~L} / \mathrm{min})$ and held for $1,2,4$ and $8 \mathrm{~h}$, respectively. While for the oxygen-limited conditions, the sealed pots were heated at 200, 250, 300, 350 and $400{ }^{\circ} \mathrm{C}$ under air-limited conditions (no air flow) or at $300,400,500,600$ and $700{ }^{\circ} \mathrm{C}$ with flowing $\mathrm{N}_{2}(2.0$ furnace volumes exchanged/min) in the muffle furnace and held for the same residence times (i.e. 1, 2, 4 and $8 \mathrm{~h}$, respectively). The temperature routine was $26^{\circ} \mathrm{C} / \mathrm{min}$ heating rate. After completion of the combustion or pyrolysis, the resulting biochars were allowed to cool to room temperature overnight under air, air-limited or $\mathrm{N}_{2}$ atmosphere. In addition, compared with the above fast pyrolyzed procedure $\left(26^{\circ} \mathrm{C} / \mathrm{min}\right)$, a slow pyrolysis $\left(20^{\circ} \mathrm{C} / 10 \mathrm{~min}\right)$ was adopted for selected peak temperatures to examine its effect on biochar properties. The charred solids at the selected conditions were collected as final biochar samples without further treatment unless specifically noted.

\subsection{Characterization of biochars}

Yields (recovery rates) of the biochars were calculated based on mass balance. Biochar $\mathrm{pH}$ values were measured at a ratio of 1:10 $(\mathrm{w} / \mathrm{v})$ in $\mathrm{KCl}$ solution $(1.0 \mathrm{~mol} / \mathrm{L})$ after being shaken for $24 \mathrm{~h}$. Elemental composition $(\mathrm{C} / \mathrm{H} / \mathrm{N} / \mathrm{S})$ of the biochars was determined using a CHN Elemental Analyzer (Varian EL III) and the oxygen content was determined by weight difference. Proximate analysis including volatile matter and ash content was conducted according to the ASTM 3174 (2011) and ASTM 3175 (2007), respectively, and fixed carbon content was determined by mass difference. Experimental error for the proximate analysis was less than $\leqslant 0.5$ wt.\%. X-ray diffraction (XRD) patterns were recorded on a PANanalytical X'Pert Pro instrument using $\mathrm{Cu} \mathrm{K} \alpha$ radiation.

Surface area and porosity of the biochars were determined via $\mathrm{N}_{2}$ adsorption using an ASAP 2020 instrument (Micromeritics Instrument). Prior to the measurement, the samples were passed through a $0.15 \mathrm{~mm}$ sieve and outgassed at $250{ }^{\circ} \mathrm{C}$ under vacuum for $4 \mathrm{~h}$. Four data points, between relative pressures of 0.05 and 0.3 , were used to construct the monolayer adsorption capacity. The total pore volume $\left(V_{\text {total }}\right)$ was estimated from a single $\mathrm{N}_{2}$ adsorbed point at a $\mathrm{N}_{2}$ relative pressure of 0.99 .

Chemical functional groups were determined by Fourier transform infrared (FTIR) spectroscopy analysis using a Bruker Vector 22 FTIR spectrometer. The spectra of the samples were recorded in the $4000-400 \mathrm{~cm}^{-1}$ region with a resolution of $4 \mathrm{~cm}^{-1}$. Biochar surface acidic functional groups were quantified using the Boehm titration method (Boehm et al., 1964). Prior to the measurement, DOC was removed from the biochars with deionized water to eliminate its effect (Fidel et al., 2013). A more detailed titration procedure description is provided in the Supporting Information (SI).

The properties of biochar-derived DOC, including contents, molecular weight distribution and specific UV absorbance at $254 \mathrm{~nm} \quad\left(\right.$ SUVA $=U_{254} \mathrm{~nm} \times 100 / D O C$, an index of relative aromaticity of DOC, Luo et al., 2011), were characterized. DOC contents in the biochars, extracted with $0.005 \mathrm{~mol} / \mathrm{L} \mathrm{NaCl}$ for $6 \mathrm{~h}$ and filtered at $0.45 \mu \mathrm{m}$, were determined using a Phoenix 8000 TOC analyzer (Malvern Co., UK). The UV absorbance was measured with a 752-UV/Vis spectrophotometer at $254 \mathrm{~nm}$ using a quartz cell with a $1-\mathrm{cm}$ path length. Apparent molecular weight distribution of DOC was estimated using high performance size exclusion chromatography. The mobile phase was $1.0 \mathrm{mmol} / \mathrm{L}$ phosphate buffer ( $\mathrm{pH} 6.8$ ) and $0.01 \mathrm{~mol} / \mathrm{L} \mathrm{NaCl}$. Further technical details can be found in Luo et al. (2011).

\subsection{Statistical analysis}

The data reported for all the chemical and physical analyses were averages of three replicates. The effects of temperature, heating rate, heating time and atmosphere on biochar properties were compared among different levels using a one-way ANOVA test, and the individual difference was investigated post hoc using a Tukey 
test with the statistical package SPSS 17.0 (SPSS Inc.). In all cases the statistical significance was based on a $p$ value $<0.05$.

\section{Results}

\subsection{Yields and elemental compositions}

The yields and elemental compositions of the biochars produced under different conditions are presented in Fig. 1 and Table 1. All the three biomass feedstocks exhibited similar trends on biochar yields regardless of atmosphere, heating temperature and time. Generally, the biochar yields were significantly decreased with increasing heating temperature and time, particularly in the presence of $\mathrm{O}_{2}$ (air-flow and air-limited atmospheres). For instance, the biochar yields were below $10 \%$ when heated at $400{ }^{\circ} \mathrm{C}$ over $1 \mathrm{~h}$ under air-limited atmosphere. In contrast, heating time showed relatively little effect on biochar yields under $\mathrm{N}_{2}$ atmosphere. For instance, the yields were only slightly affected by heating times at 500 and $600{ }^{\circ} \mathrm{C}$ for the three feedstocks. In addition, the feedstock type did not exhibit significant effects on the biochar yield under the applied conditions (Fig. S1 in SI). Compared with air-limited atmospheric, air-flow atmosphere tended to further decrease the yields of the biochars; however, the effect was insignificant for the applied temperature range $(p>0.05)$ (Fig. S2 in SI). Similarly, slow heating rate also showed a weak effect on the biochar yields (Fig. S3 in SI).

The contents of $\mathrm{C}$ and ash in the biochars tended to increase and the contents of $\mathrm{H}$ and $\mathrm{O}$ tended to decrease with increasing production temperature (Table 1 ). The content of $C$ was negatively correlated with the biochar yield regardless of production conditions, indicating the occurrence of carbonizing reactions during the production progresses. In addition, maize straw and bagasse biomass produced more ash content compared with pine sawdust (Table 1).

The content of volatile matter in the biochars significantly decreased with increasing temperature, exhibiting a similar trend with the yield. Feedstock type showed a slight effect on the volatile matter (Table S1 in SI). The volatile matter was more sensitive to the production temperature for pine sawdust and maize straw, and higher content of volatile matter was reserved in sugarcane bagasse at higher temperature. Consistent with the yields, the volatile matter tended to further decrease in the presence of $\mathrm{O}_{2}$ compared with that in the presence of $\mathrm{N}_{2}$ atmosphere, indicating higher carbonized degrees of the biomass materials.

\subsection{Surface areas}

The surface areas from mesopores and micropores of the biochars significantly increased with production temperature for the three feedstocks (Tables 1 and S2 in SI). At high temperatures $\left(>600{ }^{\circ} \mathrm{C}\right)$, the $\mathrm{N}_{2}$ surface areas tended to be less affected by pyrolysis temperature (Table S2 in SI), possibly due to the increased contents of ash in the biochars. It is necessary to note that the biochars from maize straw showed relatively low surface area compared with the other two feedstocks. In addition, increased carbonization, for instance, under air conditions or longer heating times, also tended to increase the micropore volumes and thus the surface areas of the biochars (Tables 1 and S2 in SI).

\section{3. $\mathrm{pH}$ and functional groups}

The biochar $\mathrm{pH}$ varied by feedstock and production temperature simultaneously (Fig. 2). Under $\mathrm{N}_{2}$ atmosphere, the biochar $\mathrm{pH}$ tended to increase with temperature, and measured to be 10.18 for the maize straw-derived biochar at $700{ }^{\circ} \mathrm{C}$. In contrast, the $\mathrm{pH}$ of the biochars decreased to their minima at around $250{ }^{\circ} \mathrm{C}$ and then significantly increased with production temperature under air-limited atmosphere, exhibiting upward-opening parabolic trends with increasing temperature. Among the three feedstocks, the pine sawdust-derived biochar showed the lowest $\mathrm{pH}$, followed by bagasse and maize straw under all production temperatures.

Consistent with the variation of $\mathrm{pH}$ value, the contents of surface acidic functional groups (including carboxylic groups) decreased with increasing temperature (Tables 1 and S2 in SI). In addition, the ratio of the carboxylic groups to the total acidic functional groups significantly increased with production temperature, indicating some weak acidic groups (e.g., lactonic and phenolic) were decomposed with increasing carbonization of the biomass materials.

The fact of the decreased functional groups in the biochars with increasing temperature was further evidenced by FTIR analysis (Fig. S4 in SI). The spectra of the biochar samples were characterized by 6 principle bands at the wavenumbers of 2922, 1712, $1614 / 1589,1437$ and $1262 / 1160 / 1058 \mathrm{~cm}^{-1}$, which are assigned to aliphatic $\mathrm{CH}_{2}$ (Luo et al., 2014), aromatic carboxyl/carbonyl $(C=0)$ stretching (Chun et al., 2004), aromatic $(C=C)$ stretching, $\mathrm{COOH}$ and $\mathrm{CHO}$ stretching (Chun et al., 2004), and aromatic CO- and phenolic -OH stretching (Chun et al., 2004), respectively. The compositions of pine sawdust, maize straw and sugarcane bagasse mainly differed in their contents of lignin, cellulose and hemicellulose. Thus the distribution of functional groups in the biochars, which showed similar peak positions around 1514 and $1160 \mathrm{~cm}^{-1}$, was less affected by biomass type except for the weak band of lignin $\left(1514 \mathrm{~cm}^{-1}\right)$ for maize straw while varied significantly as a function of temperature. Under $\mathrm{N}_{2}$ atmosphere, all the bands appeared with high intensities for the biochars at $300{ }^{\circ} \mathrm{C}$ and gradually decreased in their intensities with increasing
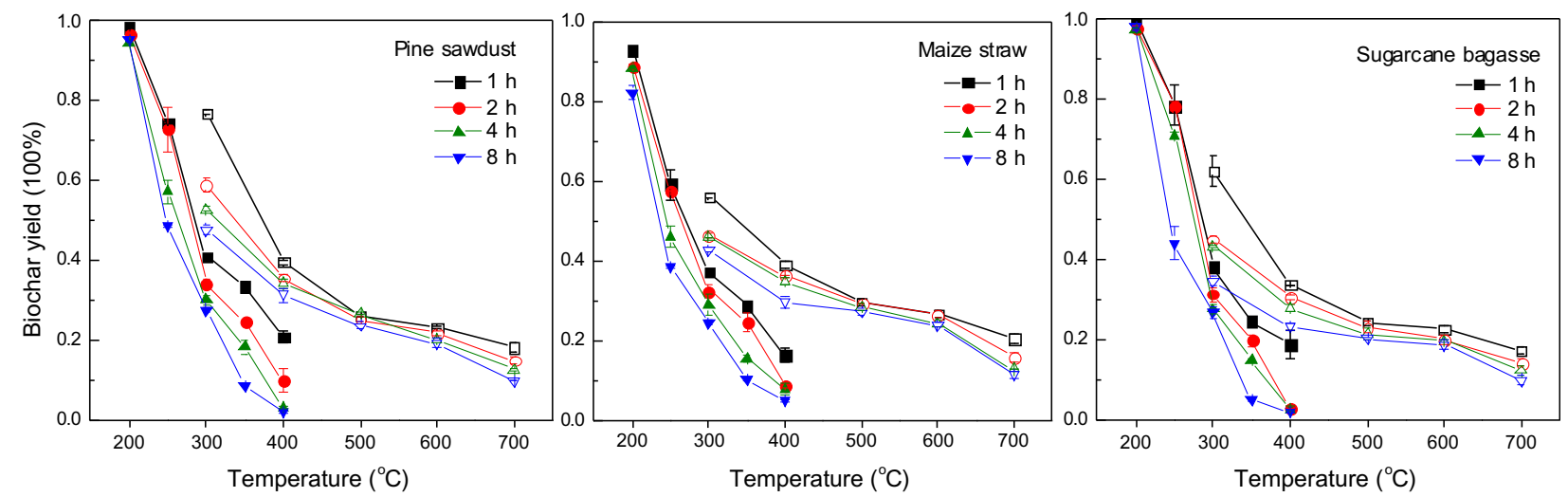

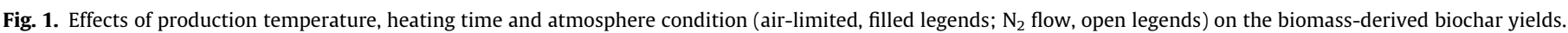


Table 1

Physicochemical properties of the biomass and selected biochars.

\begin{tabular}{|c|c|c|c|c|c|c|c|c|c|}
\hline \multirow[t]{2}{*}{ Sample } & \multicolumn{5}{|c|}{ Elemental component (wt.\%) } & \multirow[t]{2}{*}{ Ash } & \multirow{2}{*}{$\begin{array}{l}\text { Carboxylic groups } \\
\left(\mathrm{mmol} \mathrm{g}^{-1}\right)\end{array}$} & \multirow{2}{*}{$\begin{array}{l}\text { Total acidic functional groups } \\
\left(\mathrm{mmol} \mathrm{g}^{-1}\right)\end{array}$} & \multirow{2}{*}{$\begin{array}{l}\mathrm{SA}_{\mathrm{BET}} \\
\left(\mathrm{m}^{2} \mathrm{~g}^{-1}\right)\end{array}$} \\
\hline & $\mathrm{C}$ & $\mathrm{H}$ & $\mathrm{O}^{\mathrm{a}}$ & $\mathrm{N}$ & $\mathrm{S}$ & & & & \\
\hline Raw pine sawdust & 50.6 & 6.18 & 43.1 & 0.05 & 0.06 & 3.76 & - & - & - \\
\hline Raw maize straw & 42.2 & 7.21 & 49.2 & 1.28 & 0.14 & 5.31 & - & - & - \\
\hline Raw sugarcane bagasse & 48.9 & 7.11 & 42.9 & 1.02 & 0.11 & 4.98 & - & - & - \\
\hline Pine sawdust $300^{\circ} \mathrm{C}$ air-limited ${ }^{\mathrm{b}}$ & 62.1 & 5.68 & 32.1 & 0.09 & 0.07 & 6.72 & 0.46 & 1.87 & 12.1 \\
\hline Maize straw $300^{\circ} \mathrm{C}$ air-limited & 68.2 & 4.97 & 24.9 & 1.68 & 0.21 & 15.4 & 0.50 & 2.35 & 7.8 \\
\hline Sugarcane bagasse $300^{\circ} \mathrm{C}$ air-limited & 67.4 & 5.16 & 26.7 & 0.61 & 0.15 & 11.8 & 0.44 & 1.96 & 25.3 \\
\hline Pine sawdust $300^{\circ} \mathrm{C} \mathrm{N}_{2}$ & 55.3 & 5.50 & 39.0 & 0.07 & 0.13 & 4.58 & 0.45 & 2.23 & 8.2 \\
\hline Maize straw $300{ }^{\circ} \mathrm{C} \mathrm{N}_{2}$ & 57.4 & 6.64 & 34.2 & 1.59 & 0.14 & 11.3 & 0.48 & 2.70 & 2.6 \\
\hline Sugarcane bagasse $300^{\circ} \mathrm{C} \mathrm{N} \mathrm{N}_{2}$ & 58.5 & 6.73 & 34.3 & 0.42 & 0.13 & 8.87 & 0.39 & 2.42 & 12.2 \\
\hline Pine sawdust $500{ }^{\circ} \mathrm{C} \mathrm{N}_{2}$ & 76.0 & 3.54 & 19.8 & 0.15 & 0.47 & 6.91 & 0.20 & 0.38 & 68.4 \\
\hline Maize straw $500{ }^{\circ} \mathrm{C} \mathrm{N}_{2}$ & 80.7 & 3.23 & 14.1 & 1.71 & 0.30 & 17.6 & 0.27 & 0.37 & 33.2 \\
\hline Sugarcane bagasse $500^{\circ} \mathrm{C} \mathrm{N} \mathrm{N}_{2}$ & 77.7 & 3.96 & 17.5 & 0.68 & 0.15 & 12.3 & 0.23 & 0.36 & 97.8 \\
\hline
\end{tabular}

a Elemental composition was calculated on a dry-weight basis (oxygen determined by difference) and normalized to an ash-free basis.

b The biochars were produced under different conditions with a heating time of $1 \mathrm{~h}$.

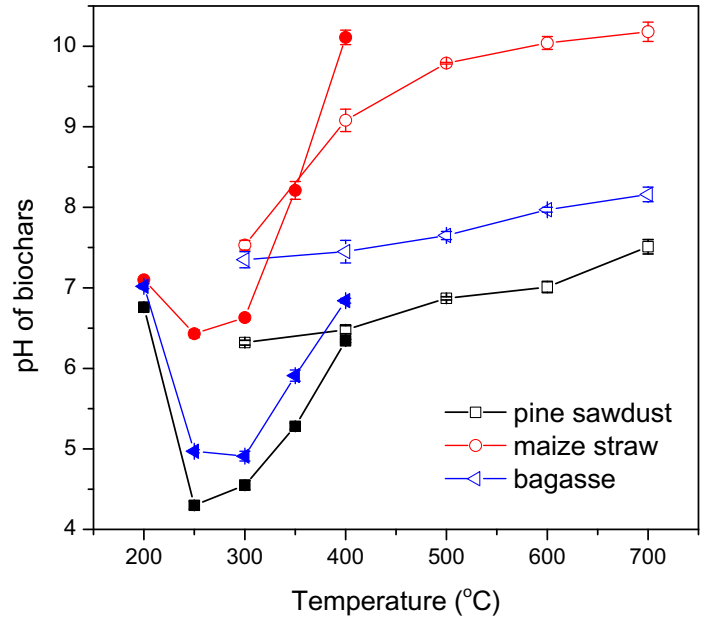

Fig. 2. The $\mathrm{pH}$ of three biomass-derived biochars produced under different conditions with a heating time of $1 \mathrm{~h}$ (filled symbols: under air-limited atmosphere; open symbols: under $\mathrm{N}_{2}$ atmosphere).

production temperature, and some (e.g., aliphatic $\mathrm{C}$ and carboxylic $\mathrm{C}=\mathrm{O})$ disappeared at high temperatures $\left(>500^{\circ} \mathrm{C}\right)$. Meanwhile, the intensity of the band at $1613 \mathrm{~cm}^{-1}$ for the aromatic stretching remained largely unchanged under the production temperatures. Under air-limited atmosphere, the distribution of the functional groups also exhibited similar trends with the production temperature, and the presence of $\mathrm{O}_{2}$ (air-flow) further favored the aromatization of the biochars (Fig. S4 in SI). Similarly, longer heating time also showed obvious effects on the distribution of the functional groups and thus the aromatization of the biochars (Fig. S5 in SI). Overall, the FTIR-derived characteristics of the biochars agreed with other characterizing results.

\subsection{Dissolved organic carbon}

During carbonizing processes, abundant DOC was released from the biochars and showed large variance as a function of temperature, exhibiting obvious upward-opening parabolic trends with temperature under both $\mathrm{O}_{2}$ and $\mathrm{N}_{2}$ atmospheres (Fig. 3). Specifically, the DOC content was significantly decreased at first with increasing temperature and reached their minima at around $500{ }^{\circ} \mathrm{C}$ and then increased at higher temperature under $\mathrm{N}_{2}$ atmosphere. Under air-limited atmosphere, the DOC contents in the biochar reached their minima at $350{ }^{\circ} \mathrm{C}$. In addition, the feedstock type also exerted significant effects on the DOC contents in the

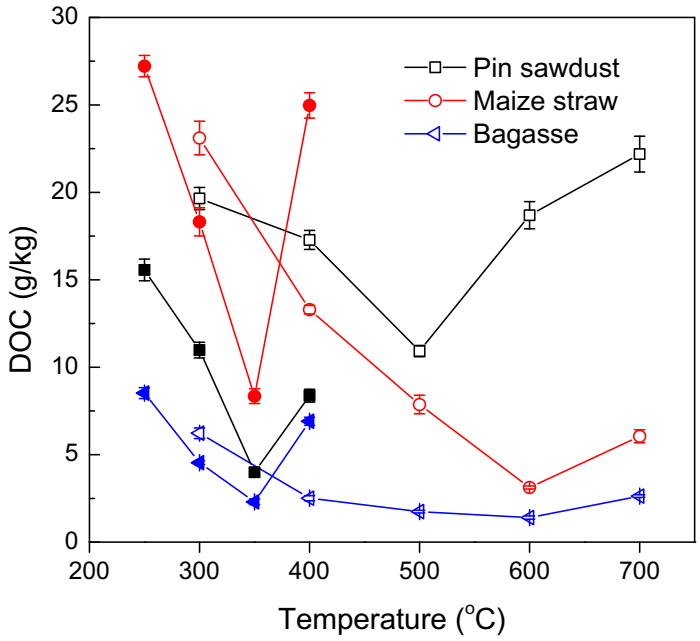

Fig. 3. The contents of DOC from three biomass-derived biochars produced under different conditions with a heating time of $1 \mathrm{~h}$ (filled symbols: under air-limited atmosphere; open symbols: under $\mathrm{N}_{2}$ atmosphere).

biochars, and sugarcane bagasse-derived biochar showed the lowest DOC content regardless of production conditions, while maize straw-derived biochar had the highest DOC content $(27.2 \mathrm{~g} / \mathrm{kg}$, Fig. 4) at $250{ }^{\circ} \mathrm{C}$ under air-limited atmosphere.

The molecular weight distribution of the biochar-derived DOC tended to increase with increasing temperature regardless of DOC content (Fig. 4). The molecular weight distribution from the three biochar-derived DOCs exhibited similar trends by presenting three main peaks, indicating that the DOC molecules were composed of a series of compounds with molecular weights smaller than $8000 \mathrm{Da}$. With increasing temperature, the peaks with longer retention times (indicating small molecular weight) tended to decrease and even disappeared at $700{ }^{\circ} \mathrm{C}$. Meanwhile, the proportion of the areas under peaks with shorter retention times tended to increase with increasing temperature. The molecular distribution of DOCs from the biochars produced under air-limited atmosphere also exhibited similar increasing trends with temperature (Fig. 4).

\section{Discussion}

A clear relationship between biochar properties and production conditions is expected. For instance, regardless of feedstock type, the yields tended to decrease under higher production 

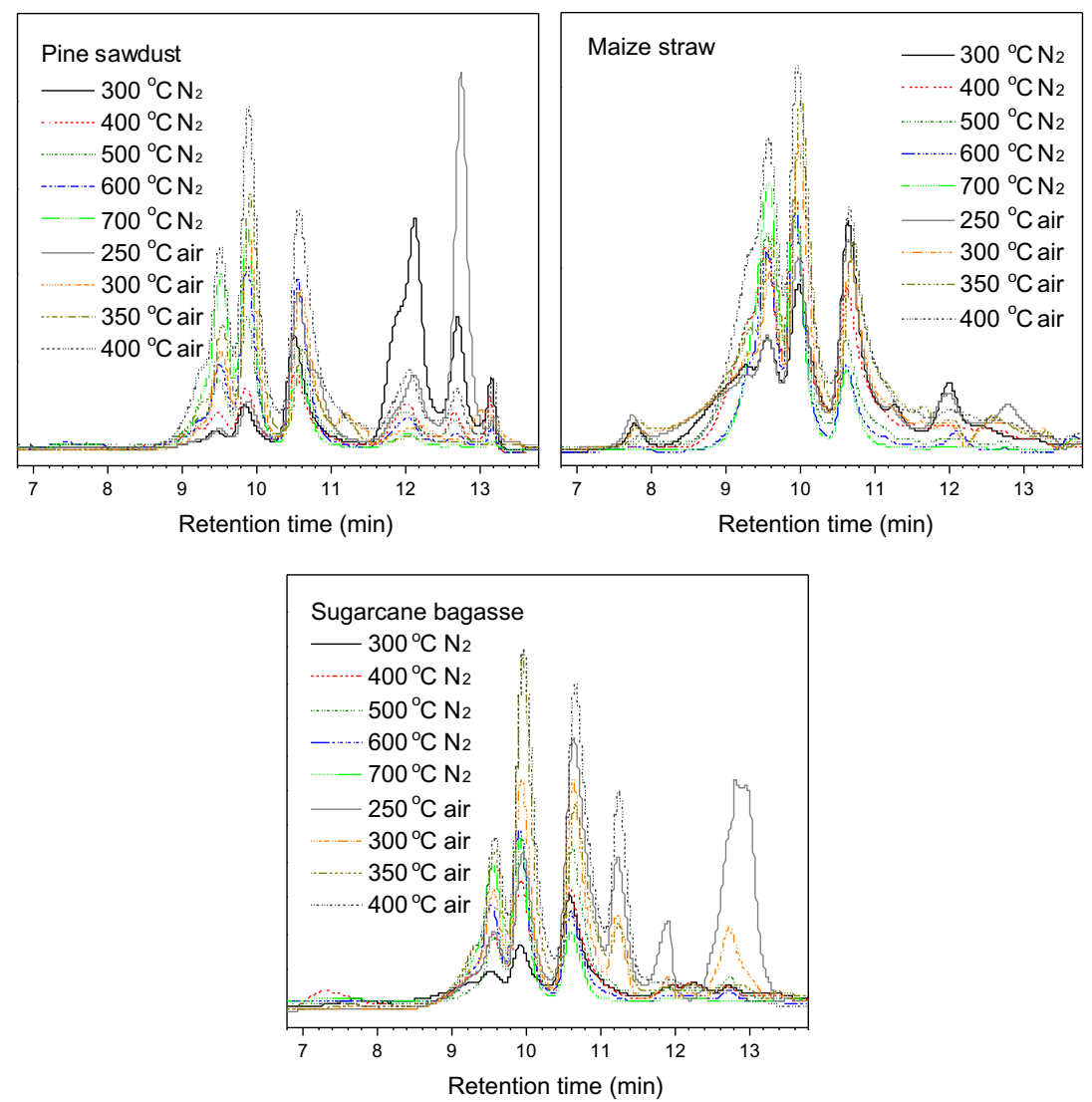

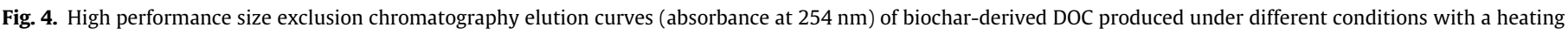
time of $1 \mathrm{~h}$.

temperature, longer heating time or the presence of $\mathrm{O}_{2}$. Among the operating conditions, both production temperature and atmosphere condition acted as predominant factors affecting the biochar properties. It is known that an increase of production temperature leads to the generation of biochars with higher fixed carbon and porosity but with lower yield (Manyà, 2012). A noteworthy inflection point at around $400{ }^{\circ} \mathrm{C}$ was observed for the effect of production temperature on biochar properties. Above $400{ }^{\circ} \mathrm{C}$, the biochar surface area was dramatically increased for the three biomass feedstocks. Keiluweit et al. (2010) observed the similar change at this temperature with this kind of biomass and ascribed the inflection point to be the recalcitrance of cellulose or lignin that resists pyrolytic decomposition at $300{ }^{\circ} \mathrm{C}$. As shown by XRD data (Fig. S6 in SI), a phase transition from layered $C$ to amorphous char occurred at around $400{ }^{\circ} \mathrm{C}$. More specifically, the cellulose crystallinity of the biomass tended to disappear at temperatures above $350^{\circ} \mathrm{C}$, while aromatic crystallites were evolved at above $400{ }^{\circ} \mathrm{C}$. The formation of highly ordered aromatic structures facilitated the development of narrow pores in the biochars with increasing temperature, leading to significant improvements in the surface areas and pore volumes (Al-Wabel et al., 2013). The presence of $\mathrm{O}_{2}$ significantly accelerated the carbonization of the biomass materials by drastic combustion, increased the aromaticity and surface area while distinctly decreased the yield ( $10 \%$ or more $\mathrm{CO}_{2}$ release) compared with those produced at the same temperature under $\mathrm{N}_{2}$ atmosphere (Figs. 1 and S4, Table S2 in SI).

Accompanying the above physical changes, the chemical structures of the biochars tended to be increasingly condensed and aromatized with increasing temperature, evidenced by the significant decrease in the volatile matter contents and the aliphatic and polar aromatic groups. Meanwhile, the relative enrichment of apolar aromatic groups confirmed by the decreased O-functionality from FTIR and elemental analyses also supported the fact of increased hydrophobic and aromatic structures in the biochars with increasing temperature (Chun et al., 2004; Uchimiya et al., 2011; Rutherford et al., 2012). The aromatic condensation in the biochars can be ascribed to the progressive dehydration, decarbonylation and decarboxylation reactions as the polycondensed aromatic structures were formed and polyaromatisation reactions (i.e. growth in the size of aromatic sheets) became dominant (Novak et al., 2009; McBeath et al., 2014). The decreased acidic groups and released alkaline salts in the biochars contributed to the increased $\mathrm{pH}$ with increasing temperature (Mukherjee et al., 2011). Because of high mineral contents (such as $\mathrm{K}$, Ca and $\mathrm{Mg}$ ) in maize straw and sugarcane, the biochars derived from them showed higher $\mathrm{pH}$ values and ash contents than those from pine sawdust (Mukherjee et al., 2011; Enders et al., 2012). The relatively lower $\mathrm{pH}$ of the biochars at $250^{\circ} \mathrm{C}$ might be related to the lower carbonization of the biomass materials and less alkaline functional groups were released. Mukherjee et al. (2011) also reported the acidic $\mathrm{pH}$ of biochars at low production temperature.

During the carbonizing processes, the DOC with lower molecular weight tended to be decomposed into $\mathrm{CO}_{2}$ with increasing temperature, exhibiting decreasing DOC contents. As the temperature further increased, some relatively stable carbons including volatile matter were decomposed into small molecules and the DOC with higher molecular weight was reserved probably due to its stable structure. The increased $\mathrm{SUVA}_{254}$ values of the biochar-derived DOC with production temperature (Fig. S7 in SI) also agreed with the changes of its molecular weight. Meanwhile, the yields of the solid biochars significantly decreased with increasing temperature. 
As a result, the proportion of DOC to biochar, i.e. DOC contents, tended to increase at higher temperatures. In addition, the differences in the temperature for the minimum DOC content under different atmospheres also confirmed the important effect of atmosphere on biochar properties.

Compared with temperature and atmosphere, heating time and rate had relatively weak effects on the biochar properties. For example, heating times within $8 \mathrm{~h}$ did not have significant effects on the functional group distributions (Fig. S5 in SI) with the exception that the yields were decreased. In contrast to previous conclusion that high heating rate resulted in a decreased yield of biochar (Angin, 2013), our results demonstrated that a higher heating rate led to higher yields of biochars under $\mathrm{N}_{2}$ atmosphere (Fig. S3 in SI), which is probably related to the shortened heating time. In addition, the effect of heating rate on the biochar yields became further attenuated at high temperatures, which is consistent with previous results (Angin, 2013). Therefore, reducing heating time (for example, a heating time of $1 \mathrm{~h}$ ) while maintaining desired properties is recommended to obtain high yields for biochar production.

A similar response of different biochar feedstocks to operating conditions provides the possibility of proposing optimized production methods for desired biochars. This study clearly demonstrated that the biochars produced at low temperature (i.e. $300{ }^{\circ} \mathrm{C}$ ) had high $\mathrm{O}$-functional group content and thus had strong hydrophilic properties which favors the sequestration of polar compounds and heavy metals (Zhu et al., 2005). In contrast, the biochars produced at higher temperatures $\left(\geqslant 500{ }^{\circ} \mathrm{C}\right)$ showed high aromaticity and hydrophobicity (Chun et al., 2004), which have strong affinity for hydrophobic organic contaminants (Mitchell and Simpson, 2013). Further increase of the production temperature at above $500^{\circ} \mathrm{C}$ exerted a weak effect on the distribution of the functional groups of the biochars while increasing the release of $\mathrm{CO}_{2}$ (decreased yields) and $\mathrm{DOC}$ (a risk-uncertained component in the environment). A compromise between the desired properties (sequestration potential for contaminants) and high yield for biochars obtained from given biomass feedstocks suggests that the temperatures of 300 and $500{ }^{\circ} \mathrm{C}$ are optimal for producing biochars with polar and apolar functionality, respectively.

\section{Conclusions}

This study demonstrated that both production temperature and atmospheric condition dramatically influenced properties of biochars and it is possible to produce desired biochars with high yield through appropriate combination of production conditions. The biochar yield, volatile matter and polar O-functional groups significantly decreased with increasing production temperature, particularly in the presence of $\mathrm{O}_{2}$. The aromaticity of the biochars was significantly enhanced at temperatures above $400{ }^{\circ} \mathrm{C}$ where a phase transition occurred for the three biomass materials. The biochar-derived DOC tended to increase its molecular weight with increasing temperature although its contents fluctuated with the temperature. Future studies should focus on the environmental implications of the biochar-derived DOC.

\section{Acknowledgements}

The work was funded by the 973 Program of China (Grant 2014CB441102), the Strategic Priority Research Program of the Chinese Academy of Sciences (XDB14020202) and the National Natural Science Foundation of China (Grants 41471269 and 21277157).

\section{Appendix A. Supplementary data}

Supplementary data associated with this article can be found, in the online version, at http://dx.doi.org/10.1016/j.biortech.2015.05. 054 .

\section{References}

Al-Wabel, M.I., Al-Omran, A., El-Naggar, A.H., Nadeem, M., Usman, A.R.A., 2013. Pyrolysis temperature induced changes in characteristics and chemical composition of biochar produced from conocarpus wastes. Bioresour. Technol 131, 374-379.

Angin, D., 2013. Effect of pyrolysis temperature and heating rate on biochar obtained from pyrolysis of safflower seed press cake. Bioresour. Technol. 128, 593-597.

ASTM Committee, 2011. Standard test method for ash in the analysis sample of coa and coke from coal. Designation: D3174-11.

ASTM Committee, 2007. Standard test method for volatile matter in the analysis sample of coal and coke. Designation: D3175-11.

Boehm, H.P., Heck, W., Sappok, R., Diehl, E., 1964. Surface oxides of carbon. Angew. Chem. Int. Ed. 3 (10), 669-677.

Chen, Z.M., Chen, B.L., Chiou, C.T., 2012. Fast and Slow rates of naphthalene sorption to biochars produced at different temperatures. Environ. Sci. Technol. 46, 11104-11111.

Cheng, C.-H., Lehmann, J., Thies, J.E., Burton, S.D., Engelhard, M.H., 2006. Oxidation of black carbon by biotic and abiotic processes. Org. Geochem. 37, 1477-1488.

Chun, Y., Sheng, G.Y., Chiou, C.T., Xing, B.S., 2004. Compositions and sorptive properties of crop residue-derived chars. Environ. Sci. Technol. 38, 4649-4655.

Enders, A., Hanley, K., Whitman, T., Joseph, S., Lehmann, J., 2012. Characterization of biochars to evaluate recalcitrance and agronomic performance. Bioresour. Technol. 114, 644-653.

Fidel, R.B., Laird, D.A., Thompson, M.L., 2013. Evaluation of modified Boehm titration methods for use with biochars. J. Environ. Qual. 42, 1771-1778.

Ghosh, U., Luthy, R.G., Cornelissen, G., Werner, D., Menzie, C.A., 2011. In-situ sorbent amendments: a new direction in contaminated sediment management. Environ. Sci. Technol. 45, 1163-1168.

Keiluweit, M., Nico, P.S., Johnson, M.G., Kleber, M., 2010. Dynamic molecular structure of plant biomass-derived black carbon (Biochar). Environ. Sci. Technol. 44, 1247-1253.

Keiluweit, M., Kleber, M., Sparrow, M.A., Simoneit, B.R.T., Prahl, F.G., 2012. Solventextractable polycyclic aromatic hydrocarbons in biochar: influence of pyrolysis temperature and feedstock. Environ. Sci. Technol. 46, 9333-9341.

Lattao, C., Cao, X.Y., Mao, J.D., Schmidt-Rohr, K., Pignatello, J.J., 2014. Influence of molecular structure and adsorbent properties on sorption of organic compounds to a temperature series of wood chars. Environ. Sci. Technol. 48, 4790-4798.

Lehmann, J., 2007. A handful of carbon. Nature 447, 143-144.

Luo, L., Zhang, S.Z., Zhang, L.C., Christie, P., 2011. Effect of phosphate on phenanthrene sorption in soils. J. Colloid Interface Sci. 353, 275-280.

Luo, L., Lv, J.T., Xu, C., Zhang, S.Z., 2014. Strategy for characterization of distribution and associations of organobromine compounds in soil using synchrotron radiation based spectromicroscopies. Anal. Chem. 86, 11002-11005.

Manyà, J.J., 2012. Pyrolysis for biochar purposes: a review to establish current knowledge gaps and research needs. Environ. Sci. Technol. 46, 7939-7954.

McBeath, A.V., Smernik, R.J., Krull, E.S., Lehmann, J., 2014. The influence of feedstock and production temperature on biochar carbon chemistry: a solid-state $13 \mathrm{C}$ NMR study. Biomass Bioenergy 60, 121-129.

Mitchell, P.J., Simpson, M.J., 2013. High affinity sorption domains in soil are blocked by polar soil organic matter components. Environ. Sci. Technol. 47, 412-419.

Mukherjee, A., Zimmerman, A.R., 2013. Organic carbon and nutrient release from a range of laboratory-produced biochars and biochar-soil mixtures. Geoderma 193-194, 122-130.

Mukherjee, A., Zimmerman, A.R., Harris, W., 2011. Surface chemistry variations among a series of laboratory-produced biochars. Geoderma 163, 247-255.

Novak, J.M., Lima, I., Xing, B.S., Gaskin, J.W., Steiner, C., Das, K.C., Ahmedna, M., Rehrah, D., Watts, D.W., Busscher, W.J., Schomberg, H., 2009. Characterization of designer biochar produced at different temperatures and their effects on a loamy sand. Ann. Environ. Sci. 3, 195-206.

Roberts, K.G., Gloy, B.A., Joseph, S., Scott, N.R., Lehmann, J., 2010. Life cycle assessment of biochar systems: estimating the energetic, economic, and climate change potential. Environ. Sci. Technol. 44, 827-833.

Rutherford, D.W., Wershaw, R.L., Rostad, C.E., Kelly, C.N., 2012. Effect of formation conditions on biochars: compositional and structural properties of cellulose, lignin, and pine biochars. Biomass Bioenergy 46, 693-701.

Sensöz, S., Angin, D., 2008. Pyrolysis of safflower (Charthamus tinctorius L.) seed press cake: Part 1 . The effects of pyrolysis parameters on the product yields. Bioresour. Technol. 99, 5492-5497.

Shen, Y.-S., Wang, S.-L., Tzou, Y.-M., Yan, Y.-Y., Kuan, W.-H., 2012. Removal of hexavalent $\mathrm{Cr}$ by coconut coir and derived chars - the effect of surface functionality. Bioresour. Technol. 104, 165-172.

Uchimiya, M., Wartelle, L.H., Klasson, K.T., Fortier, C.A., Lima, I.M., 2011. Influence of pyrolysis temperature on biochar property and function as a heavy metal sorbent in soil. J. Agric. Food Chem. 59, 2501-2510. 
Veksha, A., McLaughlin, H., Layzell, D.B., Hill, J.M., 2014. Pyrolysis of wood to biochar: increasing yield while maintaining microporosity. Bioresour. Technol. $153,173-179$.

Zhao, L., Cao, X.D., Mašek, O., Zimmerman, A., 2013. Heterogeneity of biochar properties as a function of feedstock sources and production temperatures. J. Hazard. Mater. 256-257, 1-9.
Zhu, D.Q., Kwon, S., Pignatello, J.J., 2005. Adsorption of single-ring organic compounds to wood charcoals prepared under different thermochemical conditions. Environ. Sci. Technol. 39, 3990-3998.

Zimmerman, A.R., 2010. Abiotic and microbial oxidation of laboratory-produced black carbon (biochar). Environ. Sci. Technol. 44, 1295-1301. 